\title{
Comparative Efficacy of the New Postharvest Fungicides Azoxystrobin, Fludioxonil, and Pyrimethanil for Managing Citrus Green Mold
}

\author{
Loukas Kanetis, Department of Plant Pathology, University of California, Riverside 92521; Helga Förster, De- \\ partment of Plant Pathology, University of California, Davis 95616; and James E. Adaskaveg, Department of Plant \\ Pathology, University of California, Riverside 92521
}

\begin{abstract}
Kanetis, L., Förster, H., and Adaskaveg, J. E. 2007. Comparative efficacy of the new postharvest fungicides azoxystrobin, fludioxonil, and pyrimethanil for managing citrus green mold. Plant Dis. 91:1502-1511.

Three new fungicides (i.e., azoxystrobin, fludioxonil, and pyrimethanil) are currently being introduced for postharvest management of citrus green mold in the United States. The effectiveness of each fungicide was evaluated when applied alone (at 1,000 to $1,200 \mathrm{mg} / \mathrm{liter}$ ) or in mixtures (at $500 \mathrm{mg} /$ liter each component) to lemon fruit that were wound-inoculated with imazalil/thiabendazole (TBZ)-sensitive or -resistant isolates of Penicillium digitatum. In laboratory studies when aqueous fungicide solutions were applied 9 to $21 \mathrm{~h}$ after inoculation, pyrimethanil showed the highest level of green mold control. The efficacy of fludioxonil and azoxystrobin was very high at the early timings, but decreased as time after inoculation increased. Differences in fungicide performance were not due to multiple fungicide resistance, but more likely due to differences in fungicide mobility in fruit tissue. Azoxystrobin-fludioxonil mixtures were significantly more effective when compared to single-fungicide treatments. Mixtures of imazalil with pyrimethanil were the most effective in controlling decay. The efficacy of all fungicides was significantly lower when mixed into a packing fruit coating as compared to aqueous or storage fruit coating applications. In laboratory and packingline studies, the lowest incidence of green mold decay was obtained when azoxystrobin-fludioxonil and imazalil-pyrimethanil were applied as aqueous solutions that were followed by a fruit coating. Among the new fungicides, azoxystrobin and fludioxonil applied in water or storage fruit coating, respectively, provided the best anti-sporulation activity. Storage fruit coating improved the activity of both fungicides. Pyrimethanil was the least effective fungicide in suppressing sporulation of the pathogen on decaying fruit. Overall, among the mixtures, azoxystrobin-fludioxonil and TBZ-fludioxonil had high anti-sporulation activity in aqueous and storage fruit coating applications. New integrated management programs should be based on monitoring of fungicide sensitivities in pathogen populations, rotating mixtures of products with different modes of action, and using appropriate fungicide application strategies.
\end{abstract}

Additional keywords: fungicide classes, fungicide resistance, postharvest decay control

Postharvest fungal decay contributes to the most significant crop losses to the citrus industry during storage, transportation, and marketing of orange, lemon, mandarin, and other citrus fruit (12). With lemon fruit, these problems are exacerbated because they are often stored for extended periods before marketing. Considering the costs of harvesting, packaging, storage, transportation, and marketing, as well as loss in trade confidence if fruit decay develops at the wholesale or retail market, postharvest losses have a high economic impact (14). Losses of untreated fruit from fungal decay have been estimated to be as high as $90 \%$ dur-

Corresponding author: J. E. Adaskaveg

E-mail: jim.adaskaveg@ucr.edu

Accepted for publication 2 July 2007.

doi:10.1094/PDIS-91-11-1502

(C) 2007 The American Phytopathological Society ing postharvest handling and marketing (31).

In California, the two most common decays of citrus fruit are green mold caused by Penicillium digitatum (Pers.:Fr.) Sacc. and blue mold caused by $P$. italicum Wehmer. As in other areas with a Mediterranean climate, green mold is the most important cause of postharvest decay. The high reproduction capacity of the fungus and aerial dissemination of conidia contribute to a continuous source of inoculum in citrus orchards and packinghouses. The surface of virtually every citrus fruit is contaminated with fungal spores at harvest (15). In addition, inoculum may build up to high levels in California packinghouses where citrus fruit is received, processed, and stored almost year-round. $P$. digitatum initiates infections in injuries that may occur in the orchard at harvest, during transportation, and in the packinghouse. Minor injuries to the fruit flavedo or severe injuries that expose the albedo and juice sacks may be points of entry for the patho- gen $(12,15)$. Thus, fruit handling practices have a significant impact on decay incidence. Equally important for decay management are postharvest sanitation and fungicide treatments for reducing inoculum, as well as preventing fungal growth and decay. These strategies are often the primary and most efficient methods for the management of postharvest decays $(2,4)$.

For many years, sodium $o$-phenylphenate (SOPP), thiabendazole (TBZ), and imazalil have been registered for postharvest use against citrus decays in California. Treatment efficacy using these fungicides, however, is often compromised due to the occurrence of resistant pathogen populations. In addition to isolates that are resistant to single fungicides, double- and triple-resistant isolates to all of these compounds have been identified $(7,11,22$ 24). The reduced efficacy of these fungicides combined with their periodic regulatory review and potential withdrawal or cancellation stimulated our research on new materials that could be effectively incorporated into a postharvest decay control program (2). Three compounds with different modes of action, azoxystrobin, fludioxonil, and pyrimethanil, were extensively evaluated in these studies. They are all classified as reduced-risk fungicides by the U.S. Environmental Protection Agency (16), and they have only recently been introduced for citrus in the United States. These fungicides represent the first new introductions of fungicides for postharvest use on citrus fruit since the registration of imazalil in 1981 (3).

Azoxystrobin, fludioxonil, and pyrimethanil are broad-spectrum fungicides $(20,33)$. Azoxystrobin belongs to the methoxyacrylate or quinone outside inhibitor (QoI) class of fungicides. It is used mostly to prevent spore germination and is commonly utilized as a protective treatment before or at the very early stage of disease development (8). Azoxystrobin has been registered on many different crops worldwide. A number of species of plantpathogenic fungi and oomycetes, however, have developed field or practical resistance to this class of fungicides $(5,25)$. Fludioxonil is a phenylpyrrole fungicide that inhibits spore germination, germ tube elongation, and mycelial growth and has also been reported to induce germ tube distortions and cell bursting (26). The fungicide is used as a protective treatment, 
and in the United States it has been registered against a broad range of pathogens for preharvest use on small fruits and vegetables and for postharvest use on stone fruit (19). Adaskaveg et al. (1) and others $(17,18)$ suggested that fludioxonil could also be used for postharvest control of blue mold of apple, especially because no multiple resistance has been reported between fludioxonil and thiabendazole $(17,18)$. Pyrimethanil belongs to the anilinopyrimidine class of fungicides and has been registered worldwide for preharvest use on many tree and vegetable crops. The compound is effective against diseases caused by Botrytis and Monilinia spp., Venturia inaequalis, and other pathogens $(20,26)$. Anilinopyrimidines have little effect on spore germination but strongly inhibit germ tube elongation and mycelial growth. Because they exhibit some systemic translocation in the plant tissue, they have been used as protective and curative treatments (26). Sholberg et al. (28) state that pyrimethanil is an effective fungicide for control of both blue and gray mold decays of apples and can be applied before or after harvest. It has also been reported that mixtures of cyprodinil, another anilinopyrimidine fungicide, with fludioxonil provide complete control of $P$. expansum on apples when applied after fruit infection $(18,27,28)$.

The objectives of this study were to evaluate: (i) the efficacy of postharvest applications with azoxystrobin, fludioxonil, and pyrimethanil in singlefungicide and tank mixture applications for postharvest green mold control of citrus, (ii) the anti-sporulation activity of these fungicides on decaying fruit, and (iii) the effects of postharvest fruit coatings on green mold decay control and antisporulation activity of these three compounds.

\section{MATERIALS AND METHODS}

Fruit. Lemon fruit (Citrus limon (L.) Burm. F.) cv. Eureka used in this study were grown in a research orchard at the University of California, Riverside, using commercial practices. Preharvest fungicides were not applied. After harvest, fruit were hand-washed in water with a dishwashing detergent (Joy; Procter \& Gamble, Cincinnati, $\mathrm{OH})$, rinsed with water, surface-disinfested by dipping for $2 \mathrm{~min}$ in $100 \mathrm{mg} /$ liter sodium hypochlorite, rinsed with tap water, placed into plastic fruit trays in cardboard fruit boxes, and allowed to air-dry at ambient temperature. Fruit were used the same day that they were harvested or were stored for up to 7 days at $10^{\circ} \mathrm{C}$ before use.

Fungicides and fungal isolates. Fungicides used were formulated products of azoxystrobin (Abound 2.08F; Syngenta Crop Protection, Greensboro, NC), fludioxonil (Scholar 50WP; Syngenta), imazalil (Freshgard 700; Janssen Pharmaceutica,
Titusville, NJ), pyrimethanil (Penbotec 400SC; Janssen Pharmaceutica; Scala 400SC; Bayer CropScience, Kansas City, $\mathrm{MO}$ ), and thiabendazole (Mertect 340-F; Syngenta). All fungicide concentrations were based on the active ingredient. Application rates in single-fungicide treatments were 1,200 mg/liter for azoxystrobin and fludioxonil and 1,000 mg/liter for imazalil and pyrimethanil. In the applications of mixtures, the rate for all fungicides was $500 \mathrm{mg} / \mathrm{liter}$.

Two single-spore isolates of $P$. digitatum with different sensitivities to imazalil and thiabendazole were used for inoculation. Isolate $\mathrm{Pd}$ was sensitive to imazalil and thiabendazole $\left(\mathrm{EC}_{50}\right.$ values for mycelial growth 0.05 and $0.08 \mathrm{mg} / \mathrm{liter}$, respectively), and isolate 2152 was resistant to both fungicides $\left(\mathrm{EC}_{50}\right.$ values 0.65 and $>7.82 \mathrm{mg} /$ liter, respectively). Isolates were maintained as mycelial plugs in sterile water at $4^{\circ} \mathrm{C}$ for up to 1 year. For conidial production, mycelial plugs were transferred to potato dextrose agar (PDA; Difco Laboratories, Detroit, MI), and petri dishes were incubated for 5 to 10 days at $25^{\circ} \mathrm{C}$. Spore inoculum was prepared in an aqueous dilution $(0.01 \% \mathrm{vol} / \mathrm{vol})$ of Tween 20 (Sigma-Aldrich, St. Louis, MO) and adjusted to $10^{6}$ conidia/ml with sterile water. Fruit inoculation methods are described below for specific experiments.

Effect of treatment times after inoculation on the efficacy of new fungicides in managing green mold. Lemon fruit were punctured (one wound per fruit) with a $1 \times 2 \mathrm{~mm}$ nail-like, stainless steel probe without injuring the juice sacks below the albedo. For inoculation, a $20-\mu \mathrm{l}$ drop of inoculum from either isolate of $P$. digitatum was placed on each wound. Boxes with the fruit in plastic trays were then covered with plastic bags and incubated at $20^{\circ} \mathrm{C},>90 \%$ relative humidity. To evaluate the postinfection activity of aqueous single fungicides and fungicide mixtures, fruit were treated after incubation periods of 9 , $12,15,18$, or $21 \mathrm{~h}$. In single-fungicide treatments, the efficacy of azoxystrobin, fludioxonil, and pyrimethanil was compared with that of imazalil, whereas in fungicide mixture treatments, mixtures of azoxystrobin with fludioxonil and of TBZ with fludioxonil were compared with a mixture of imazalil and pyrimethanil. Fruit were sprayed with aqueous fungicide solutions on the inoculated side using a handoperated atomizer (Model 15-RD; DeVilbiss Health Care, Somerset, PA) at approximately $1 \mathrm{ml}$ per fruit. Fruit of the control treatment were sprayed with water. Fruit were then incubated in fruit boxes for 6 to 7 days at $20^{\circ} \mathrm{C},>90 \%$ relative humidity. Treatments were randomized among boxes, and boxes were covered with plastic bags. For evaluation, fruit were inspected carefully for green mold development that was either easily visible as mycelium- or conidia-covered decay or was present as soft, often watery lesions around the inoculation site. Decay incidence was calculated based on the number of decayed fruit of the total number of fruit inoculated. There were four or five replications of 10 to 12 fruit for each treatment, and the experiment was done twice.

Effect of new fungicides prepared in water or in a fruit coating on sporulation of $P$. digitatum on infected fruit. Lemon fruit were inoculated at the center with $100 \mu \mathrm{l}$ of a conidial suspension of either isolate of $P$. digitatum using a hypodermic syringe with a 16-gauge, 25-mmlong needle. Fruit were placed in plastic trays in fruit boxes and stored as described above. After 16 to $18 \mathrm{~h}$ at $20^{\circ} \mathrm{C}$ and $>90 \%$ relative humidity, fruit were dipped for 30 $\mathrm{s}$ in fungicide solutions that were prepared in water or in a diluted polyethylene-based storage fruit coating (Decco-Lustr 202; Decco-Cerexagri, King of Prussia, PA; 1 part fruit coating diluted with 14 parts water). Single-fungicide treatments or mixtures (i.e., azoxystrobin-fludioxonil, TBZ-fludioxonil, or imazalil-pyrimethanil) were used. Control fruit were dipped in water or diluted storage fruit coating. Treated fruit were allowed to air-dry and were then incubated at $20^{\circ} \mathrm{C}$ and $>90 \%$ relative humidity as described above.

The degree of sporulation was determined when the surface of the control fruit was completely covered with spores (generally 6 to 7 days after inoculation). Fungal sporulation was rated using a scale from 0 to 4 where $0=$ no or negligible sporulation and 4 = fruit completely green and fungal sporulation over the entire surface. There were four replications of 12 fruit for each treatment, and the experiment was done twice.

Effect of postharvest fruit coatings on fungicide efficacy in the control of green mold. In laboratory studies, fruit were inoculated as described above using conidia of the imazalil- and TBZ-sensitive $P$. digitatum isolate $\mathrm{Pd}$ and treated with fungicides after 13 to $15 \mathrm{~h}$. Fungicide solutions were either in water or in a fruit coating. The aqueous dilution of a polyethylene-based storage fruit coating was prepared as described previously, whereas a shellac-based packing fruit coating (Decco Citrus Lustr 400; Decco-Cerexagri) was used undiluted. Additionally, aqueous fungicide applications were followed by an application with shellac-based fruit coating that did not contain fungicide. Fruit of the control treatment were only sprayed with water or with each of the fruit coatings. Fruit treated with shellac-based fruit coating were dried for $30 \mathrm{~min}$ at $37^{\circ} \mathrm{C}$, and all fruit were then incubated and evaluated for decay as described above. There were four or five replications of 10 to 12 fruit for each treatment, and the experiment was done twice.

An experimental packingline study using fungicide mixtures was conducted at 
the University of California Kearney Agricultural Center in Parlier, CA, where lemon fruit were treated 13 to $14 \mathrm{~h}$ after wound-inoculation with the imazalil/TBZresistant isolate of $P$. digitatum. Highvolume, in-line drenches were applied to lemon fruit by pumping a fungicide solution from a 70-liter reservoir to a perforated steel distribution pan $(91 \times 91 \mathrm{~cm}$ area with 127 5-mm holes evenly distributed) over a moving roller bed. Fungicide rates were as described above, and treatment volumes were equivalent to $33 \mathrm{li}$ ter $10,000 \mathrm{~kg}$ fruit. Fruit coatings were used undiluted (packing fruit coating) or diluted to 1 to $14(\mathrm{vol} / \mathrm{vol})$ with water (storage fruit coating). Fruit coatings were applied after the fungicide drenches using low-volume spray applications with a controlled droplet applicator (CDA; DeccoCerexagri) that was positioned in the center of the treatment area and ca. $20 \mathrm{~cm}$ above the roller bed. Treatment volumes for the spray applications of fruit coatings were adjusted to 8.3 liter $/ 10,000 \mathrm{~kg}$ fruit by regulating fruit coating output volumes and speed of fruit movement through the treatment area. Treatment times were generally between 12 and $15 \mathrm{~s}$. Control fruit were treated only with the fruit coatings. Between treatments, fungicide reservoirs and tubing, as well as treatment beds, were treated with a commercial alkaline detergent (PacFoam Plus; Pace International, Seattle, WA) and then thoroughly rinsed with water. There were four replications of 24 fruit for each treatment, and the experiment was done twice. Fruit were incubated and evaluated for decay as described above.

Statistical analysis of data. Data for decay incidence were arcsine transformed. Bartlett's test for homogeneity of variances was performed for repeated experiments. Because variances were homogeneous $(P<$ 0.05 ), combined data sets were then analyzed using a balanced factorial arrangement. The effects of fungicide treatments were evaluated for their efficacy in decay or sporulation control in applications with water or fruit coatings in a completely randomized (fungicides) or balanced factorial randomized complete block (fungicides and fruit coatings) arrangement. Transformed values were analyzed using general linear model or analysis of variance and least significant difference mean separation procedures of SAS version 9.1 (SAS Institute, Cary, NC). Regression analysis was used to evaluate timings of fungicide applications on the average incidence of decay using SAS. Using an analysis of covariance, regression lines for each fungicide treatment that was applied at $9,12,15,18$, or $21 \mathrm{~h}$ after inoculation were compared to determine if the slopes were equal to zero (null hypothesis; $\mathrm{H}_{0}: \beta_{1}$ $=\beta_{2}=\beta_{3}=\beta_{4}=0$ ) and to determine if the regression lines had a common slope $\left(\mathrm{H}_{0}: \beta_{1}=\beta_{2}=\beta_{3}=\beta_{4}=\beta\right)$. Additionally, regression lines with common slopes were compared for least significant means (LSmeans) at the midpoint, whereas regressions with different slopes were compared at each time after inoculation using mixed model procedures of SAS ver. 9.1.

\section{RESULTS}

Effect of treatment times after inoculation on the efficacy of new fungicides in managing green mold. The incidence of green mold decay was regressed on time after inoculation for each of the four single-fungicides (i.e., azoxystrobin, fludioxonil, pyrimethanil, and imazalil) (Fig. $1 \mathrm{~A}$ and $\mathrm{B}$ ) or of the three mixtures evaluated (i.e., azoxystrobin-fludioxonil, TBZfludioxonil, and imazalil-pyrimethanil) (Fig. 1C and D) in the analyses of covariance. For the single- and mixed-fungicide studies using both the resistant and sensitive isolates of $P$. digitatum, the null hypotheses that the slopes of the regression lines were equal to zero $\left(\beta_{\mathrm{i}}=0\right)$ and the hypothesis that all slopes were equal $\left(\beta_{\mathrm{i}}=\right.$ $\beta)$ were rejected $(P<0.01)$. This indicated that the comparative efficacy of the treatments among the single- and mixtureapplications was significantly different over time.

In the regressions for the singlefungicide treatments after inoculations with either isolate of $P$. digitatum, all fungicides significantly reduced the incidence of decay from that of the nontreated control. Regression lines for azoxystrobin and fludioxonil had positive slopes and $y-$ intercepts at or near zero, indicating that the performance of these two treatments decreased when applications were delayed over time after inoculation (Fig. 1A and B). The regression line for pyrimethanil had a slope of zero. Thus, this fungicide performed similarly at the different application times. For imazalil, the slope was equal to zero in inoculations with the imazalil/TBZ-sensitive isolate of $P$. digitatum, but was positive for the resistant isolate. Because for the sensitive isolate, regression lines for azoxystrobin and fludioxonil had common slopes and their LSmeans at the midpoint were significantly different $(P=0.006)$, the performance of these two fungicides decreased similarly over time, but their overall efficacy was significantly different, with azoxystrobin being the less effective material. Unequal slope models were used to compare regression lines of azoxystrobin and fludioxonil with those of pyrimethanil and imazalil. In this regression analysis, the LSmeans (i.e., decay incidence) for azoxystrobin and fludioxonil at $12,15,18$, and $21 \mathrm{~h}$, but not at 9 $\mathrm{h}$ after inoculation, were significantly different from those for the regressions of imazalil and pyrimethanil. Thus, these latter two fungicides were significantly more effective than azoxystrobin or fludioxonil when treatments were delayed for more than $9 \mathrm{~h}$ after inoculation with an
imazalil/TBZ-sensitive isolate of $P$. digitatum (Fig. 1A). For the resistant isolate, regressions of azoxystrobin, fludioxonil, and imazalil were found to have common slopes (Fig. 1B). The LSmeans at the midpoint were not significantly different $(P=$ 0.51 ) for the regression lines of azoxystrobin and imazalil, and therefore these two treatments performed similarly over time. The LSmean of fludioxonil, however, was significantly different $(P<0.01)$ from those of azoxystrobin and imazalil, and fludioxonil was the less effective material. In the regression analysis using unequal slope models, the LSmeans at $12,15,18$, and $21 \mathrm{~h}$, but not at $9 \mathrm{~h}$ after inoculation, for the regressions of azoxystrobin, imazalil, and fludioxonil were significantly different $(P<0.01)$ from those of pyrimethanil. Thus, decay caused by an imazalil/TBZ-resistant isolate of $P$. digitatum was more effectively managed by pyrimethanil than by azoxystrobin, imazalil, or fludioxonil when treatments were delayed for more than $9 \mathrm{~h}$ after inoculation.

In the regressions for the mixedfungicide treatments, after inoculations with either isolate of $P$. digitatum, all treatments significantly reduced the incidence of decay from that of the nontreated control where $85 \%$ of the fruit developed green mold decay (Fig. 1C and D). For the sensitive isolate, the regressions of the mixtures of imazalil-pyrimethanil and TBZ-fludioxonil had a common slope, and the LSmeans at the midpoint $(15 \mathrm{~h})$ were not significantly different $(P=0.079)$. Thus, no differences in efficacy could be found between these two mixtures (Fig. 1C). These mixtures were then compared to the azoxystrobin-fludioxonil mixture using unequal slope models. The regression of azoxystrobin-fludioxonil had LSmeans at $12,15,18$, and $21 \mathrm{~h}$, but not at $9 \mathrm{~h}$ after inoculation, that were significantly different $(P<0.01)$ from those of imazalil-pyrimethanil or TBZ-fludioxonil. Thus, decay caused by a sensitive isolate of $P$. digitatum was more effectively managed by imazalil-pyrimethanil or TBZfludioxonil than by azoxystrobinfludioxonil when treatments were delayed for more than $9 \mathrm{~h}$ after inoculation.

For the resistant isolate, the regressions of the mixtures of TBZ-fludioxonil and azoxystrobin-fludioxonil had a common slope, and the LSmeans at the midpoint $(15 \mathrm{~h})$ were significantly different $(P<$ $0.01)$. Thus, the TBZ-fludioxonil mixture was less effective than azoxystrobinfludioxonil against the imazalil/TBZresistant isolate (Fig. 1D). The imazalilpyrimethanil mixture performed significantly $(P<0.01)$ better than the other two mixtures.

Effect of new fungicides prepared in water or fruit coatings on sporulation of $P$. digitatum on infected fruit. The efficacy of fungicide treatments to reduce 
sporulation of $P$. digitatum on infected fruit was evaluated after single-fungicide and mixture treatments. Fungicides were applied as aqueous solutions or in a diluted storage fruit coating. In the general linear model analysis for the single-fungicide treatments, fungicide and fungicide preparation (i.e., aqueous or diluted storage fruit coating) significantly $(P<0.01)$ affected the degree of sporulation of the imazalil/TBZ-sensitive and -resistant isolates of $P$. digitatum. In addition, there was a significant interaction $(P<0.01)$ between type of fungicide preparation and fungicide, and therefore, the type of fungicide preparation used in the dip application affected fungicide efficacy. Thus, data are presented separately for aqueous and fruit coating applications (Fig. 2).

In inoculations with the sensitive isolate, sporulation after aqueous applications of azoxystrobin, fludioxonil, or pyrimethanil was significantly reduced. Ratings were between 1.7 and 2.5 as compared to the water-treated control, which had a sporulation rating near 4 (fruit completely green and fungal sporulation over the entire surface) (Fig. 2A). No sporulation was observed after treatment with imazalil. In applications in the fruit coating, low sporulation ratings $(\leq 0.77)$ were obtained for imazalil, as well as for fludioxonil and azoxystrobin, whereas for pyrimethanil abundant conidia were produced by the pathogen as indicated by a rating of 3.0 (Fig. 2B). In inoculations with the imazalil/TBZ-resistant isolate of $P$. digitatum, similar results were obtained for azoxystrobin, fludioxonil, and pyrimethanil using both types of fungicide preparation as in the inoculations with the sensitive isolate. Again, azoxystrobin and fludioxonil performed better when applied in diluted storage fruit coating (Fig. 2D) as compared with aqueous preparations (Fig. 2C). Pyrimethanil was not very effective in aqueous or storage fruit coating preparations (Fig. 2C and D). For imazalil, however, a similar degree of sporulation was observed as in the control in these trials where fruit were inoculated with a resistant isolate.

In experiments using fungicide mixtures at rates of each fungicide approximately half of the single-fungicide applications, there were again differences in efficacy for the two types of fungicide preparations. In the general linear model analyses, the models and the fungicide mixtures were significant $(P<0.01)$ for both the sensitive and resistant isolates used in inoculations. The type of fungicide preparation was highly significant $(P<0.01)$ in inoculations with the resistant isolate and significant $(P=0.02)$ in inoculations with the sensitive isolate of $P$. digitatum. Furthermore, a significant interaction $(P<0.01)$ occurred among the fungicide mixtures and their preparation. For the azoxystrobin-fludioxonil and TBZ-fludioxonil
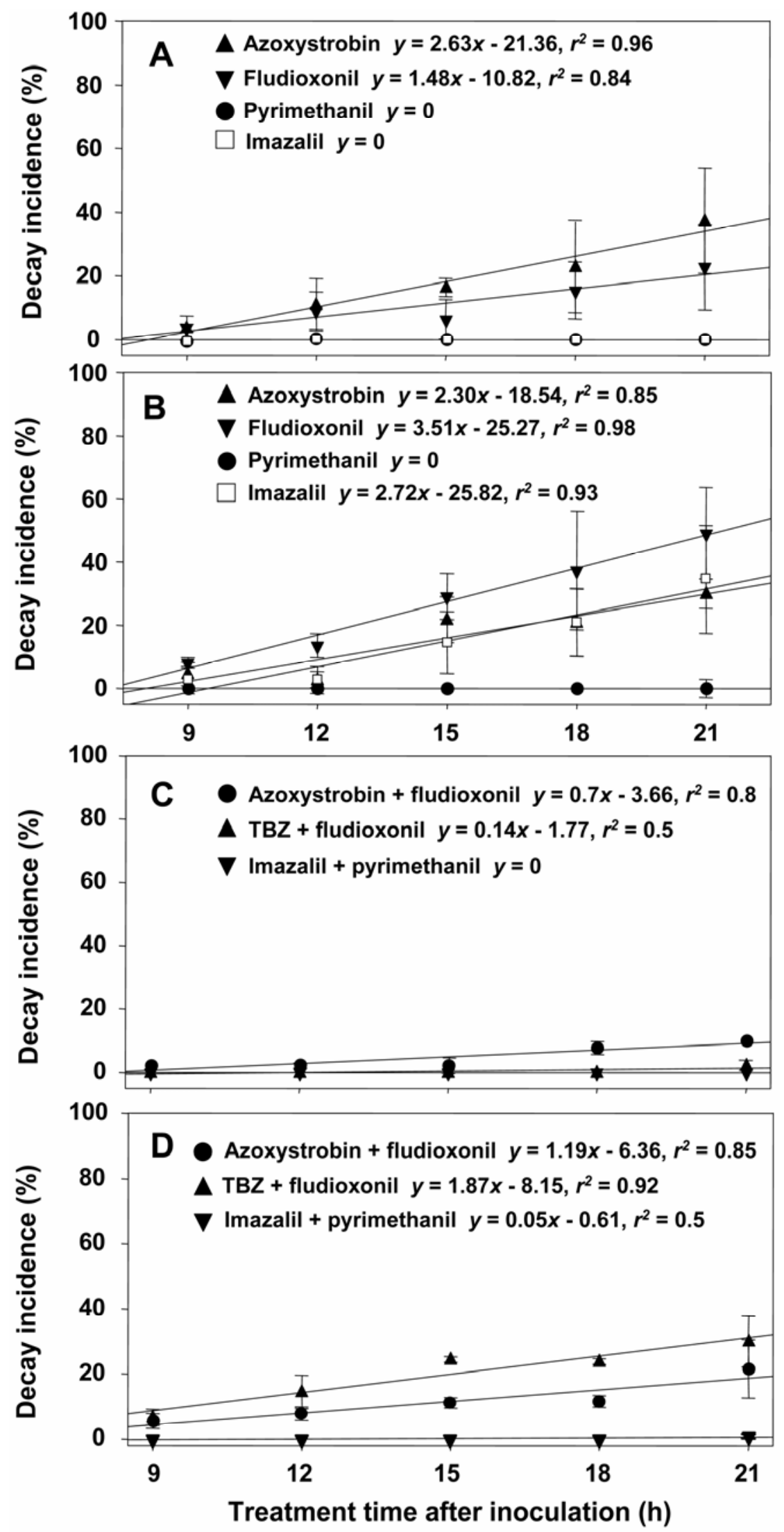

Fig. 1. Effect of treatment times after inoculation on the efficacy of fungicides in managing green mold of lemon fruit in laboratory studies. Fruit were treated with aqueous solutions of (A and B) single fungicides $(1,200 \mathrm{mg} / \mathrm{liter}$ for azoxystrobin and fludioxonil, $1,000 \mathrm{mg} / \mathrm{liter}$ for imazalil and pyrimethanil) or (C and D) mixtures of fungicides ( $500 \mathrm{mg} /$ liter for each fungicide) at selected times after wound-inoculation with conidia of Penicillium digitatum $\left(20 \mu \mathrm{l}\right.$ of $10^{6}$ conidia/ml) of (A and C) an isolate sensitive or (B and D) an isolate resistant to imazalil and thiabendazole. The incidence of fruit decay was evaluated after 6 to 7 days of incubation at $20^{\circ} \mathrm{C}$. Vertical error bars represent standard errors calculated for each treatment and timing. 
mixtures using either isolate of $P$ digitatum in the inoculations, applications in diluted storage fruit coating provided better sporulation control (ratings of 0.23 to 0.82 and 1.26 to 1.69 , respectively) than in aqueous applications (ratings of 1.08 to 1.98 and 3.72 to 3.96 , respectively) (Fig. $3 \mathrm{~A}$ to $\mathrm{D})$. In addition, the azoxystrobinfludioxonil mixture was significantly more effective than the TBZ-fludioxonil mix- ture. For the imazalil-pyrimethanil mixture (after inoculation with the imazalil/TBZsensitive isolate), however, aqueous applications performed better than the storage fruit coating preparation (Fig. 3A and B).

Effect of postharvest fruit coatings on fungicide efficacy for managing green mold. Azoxystrobin, fludioxonil, pyrimethanil, and imazalil were evaluated for their efficacy in reducing the incidence of

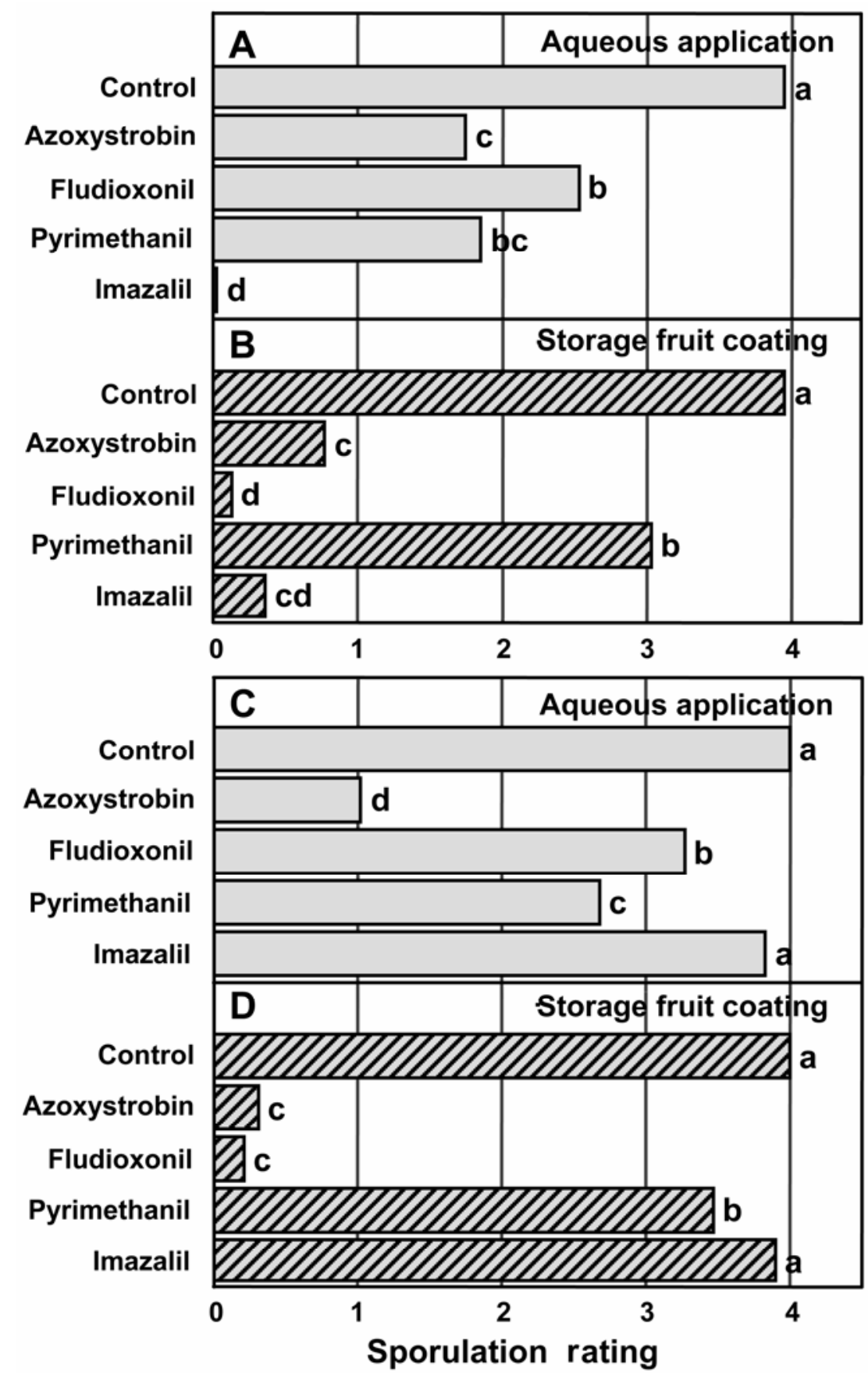

Fig. 2. Effect of postharvest fungicide treatments on sporulation of Penicillium digitatum on infected lemon fruit in laboratory studies. Fruit were inoculated into the center with conidia of $P$. digitatum (100 $\mu \mathrm{l}$ of $\left.10^{6} \mathrm{conidia} / \mathrm{ml}\right)$ of (A and B) an isolate sensitive or (C and D) an isolate resistant to imazalil and thiabendazole and treated after 16 to $18 \mathrm{~h}$ with fungicide solutions $(1,200 \mathrm{mg} / \mathrm{liter}$ for azoxystrobin and fludioxonil, 1,000 mg/liter for imazalil and pyrimethanil) prepared in (A and C) water or (B and D) a diluted storage fruit coating. Fungal sporulation was evaluated after 6 to 7 days of incubation at $20^{\circ} \mathrm{C}$ using a scale from 0 to 4 where $0=$ no or negligible sporulation and $4=$ fruit completely green and fungal sporulation over the entire surface. Means followed by the same letter are not significantly different according to a general linear model analysis and LSD mean separation test $(P<0.05)$. green mold after inoculation with an isolate of $P$. digitatum that was sensitive to imazalil and TBZ. Similarly, fungicide mixture applications (azoxystrobin-fludioxonil, TBZ-fludioxonil, and pyrimethanil-imazalil) were evaluated for their efficacy after inoculation with an isolate that was resistant to imazalil and TBZ. In the two statistical analyses, treatments of lemon fruit with single fungicides or mixtures of fungicides that were applied either as preparations in two different fruit coatings or as aqueous solutions that were followed by an application with packing fruit coating, resulted in significant effects of fungicides $(P<0.01)$ and fungicide preparation $(P<0.01)$ as indicated by the general linear model analysis. In addition, there was a significant $(P<0.01)$ interaction between fungicide and preparation/application strategy, and thus, fungicide treatments performed significantly differently in the three preparations. Thus, efficacy among the four fungicides and the three mixtures is compared separately for each of the three preparations or application strategies (Figs. 4 and 5).

For the single-fungicide applications, all fungicides in each of the preparations or application strategies significantly reduced the incidence of decay from that of the control, where $82.9 \%$ of the fruit showed symptoms of green mold. When fungicides were applied in diluted storage fruit coating, decay incidence among the treatments ranged from 0 to $10.0 \%$ (Fig. 4A). The effectiveness of pyrimethanil was similar to that of imazalil, whereas azoxystrobin and fludioxonil were somewhat less effective. Following application of the fungicides in packing fruit coating, a wider range of efficacies was observed (Fig. 4B). Again, pyrimethanil with $2.2 \%$ decay performed similarly to imazalil ( $7.8 \%$ decay). Significantly more decay was observed for azoxystrobin and fludioxonil with 25.6 and $34.4 \%$ incidence, respectively. All four fungicides reduced green mold incidence to very low levels ( 0 to $2.8 \%$ ), and there were no differences in efficacy among fludioxonil, pyrimethanil, and imazalil when used as aqueous preparations that were followed by an application with packing fruit coating (Fig. 4C).

In fungicide mixture applications in the laboratory, all treatments in each of the preparations or application strategies significantly $(P<0.01)$ reduced the incidence of decay caused by the imazalil/TBZresistant isolate of $P$. digitatum from that of the control, where more than $80 \%$ of the fruit showed symptoms of green mold (Fig. 5A to C). As in the single-fungicide treatments, aqueous applications of the fungicide mixtures followed by packing fruit coating were the most effective (Fig. 5C) and fungicides applied in the packing fruit coating were the least effective (Fig. $5 B)$. In aqueous fungicide treatments that were followed by packing fruit coating, no 
significant difference was observed between the imazalil-pyrimethanil and azoxystrobin-fludioxonil mixtures. The TBZfludioxonil mixture also performed well with $10.4 \%$ decay. In each of the fungicide preparations/application strategies, the pyrimethanil-imazalil mixture had significantly less decay incidence than the other two mixtures, whereas TBZ-fludioxonil was the least effective.

In fungicide mixture applications in the experimental packingline study where aqueous fungicide treatments were followed by either storage or packing fruit coating, the general linear model analysis indicated that the mixtures performed highly significantly different, whereas the application methods $(P=0.52)$ and the interaction of application methods and fungicide treatment $(P=0.62)$ had no significant effect. Thus, data were combined for further analyses. Similar to the laboratory studies, imazalil-pyrimethanil and azoxystrobin-fludioxonil mixture treatments were significantly $(P<0.01)$ more effective than TBZ-fludioxonil, and decay incidence was reduced to 0.6 and $6.9 \%$, respectively, as compared to the control with $70.1 \%$ decay (Fig. 6). Decay incidence for the TBZ-fludioxonil treatment was $14.3 \%$. All three fungicide mixtures followed by either fruit coating had significantly $(P<0.01)$ less decay than the control.

\section{DISCUSSION}

Due to the ubiquitous importance of green mold in citrus production (12), the widespread occurrence of isolates of $P$. digitatum resistant to imazalil and TBZ (7), and possible regulatory changes, new postharvest compounds for management of green mold decay of citrus fruit have been developed and are currently being registered worldwide. We first began to identify and develop, in collaboration with the registrants, new postharvest fungicides for managing green mold and other postharvest decays of citrus fruit in the late 1990s $(2,3)$. The efficacy of azoxystrobin and pyrimethanil was also evaluated by others, and both materials were found to be very effective in the control of citrus green mold $(9,30)$. In the current study, we included an additional fungicide, fludioxonil, that we previously identified for postharvest use on stone and pome fruits $(1,19)$. Here, we present for the first time the comparative efficacy of azoxystrobin, fludioxonil, and pyrimethanil for management of citrus green mold decay. Because sporulation of $P$. digitatum on decayed citrus fruit is a major source of inoculum in citrus packing and storage facilities, and because these spores are targets of selection for fungicide resistance, the antisporulation activity of these fungicides was also studied. Additionally, we compared the performance of these fungicides in selected mixtures and in solutions with fruit coatings. Results from these studies will help to establish use patterns for these fungicides to provide maximum decay control and anti-sporulation activity and to maintain their efficacy by implementing proper resistance management strategies.

In in vitro sensitivity studies with azoxystrobin, fludioxonil, and pyrimethanil, J. Adaskaveg et al. (3) demonstrated that all isolates of a baseline population of $P$. digi- tatum were sensitive to these fungicides irrespective of their sensitivity to imazalil and TBZ. In the present study, a representative of an imazalil/TBZ-sensitive isolate and a resistant isolate were used in fruit inoculations. Azoxystrobin, fludioxonil, and pyrimethanil, each belonging to a different class of chemicals (33), exhibited different properties that determined their efficacy against green mold decay. In the

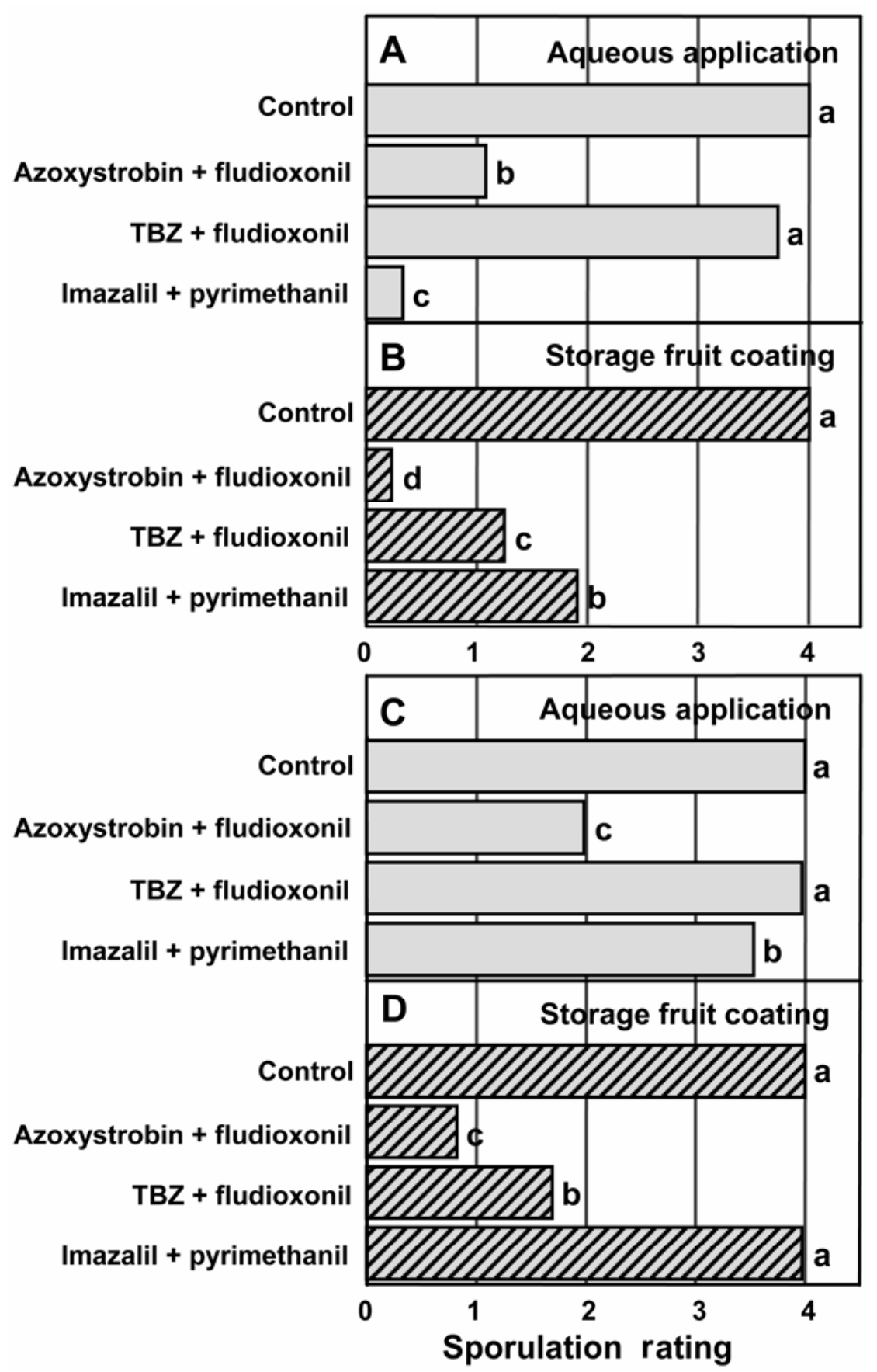

Fig. 3. Effect of postharvest treatments with selected fungicide mixtures on sporulation of Penicillium digitatum on infected lemon fruit in laboratory studies. Fruit were inoculated into the center with conidia of $P$. digitatum $\left(100 \mu \mathrm{l}\right.$ of $10^{6}$ conidia/ml) of (A and B) an isolate sensitive or (C and D) an isolate resistant to imazalil and thiabendazole and treated after 16 to $18 \mathrm{~h}$ with fungicide solutions $(500$ $\mathrm{mg} / \mathrm{liter}$ for each fungicide) prepared in (A and $\mathbf{C}$ ) water or (B and $\mathbf{D}$ ) a diluted storage fruit coating. Fungal sporulation was evaluated after 6 to 7 days of incubation at $20^{\circ} \mathrm{C}$ using a scale from 0 to 4 where $0=$ no or negligible sporulation and $4=$ fruit completely green and fungal sporulation over the entire surface. Means followed by the same letter are not significantly different according to a general linear model analysis and LSD mean separation test $(P<0.05)$. 
time study using aqueous fungicide solutions, pyrimethanil displayed the highest level of green mold control caused by both isolates of $P$. digitatum. In applications 21 $\mathrm{h}$ after inoculation, when the pathogen presumably had penetrated into fruit tissue, pyrimethanil performed with locally systemic-like activity, and no decay developed on the treated fruit. In contrast, the efficacy of fludioxonil and azoxystrobin was very high at the early timings, but decreased as time after inoculation increased from 9 to $21 \mathrm{~h}$, demonstrating their protective, nonsystemic activity. Selected mixture treatments were evaluated based on recommendations by the registrants of the fungicides. When azoxystrobin and fludioxonil were used in a mixture at approximately half-rate of the single-fungicide treatments, efficacy was significantly improved as compared to the single-fungicide treatments, demonstrating an additive ef- fect of these two fungicides. Decay incidence after inoculation with the imazalil/TBZ-sensitive and -resistant isolates of $P$. digitatum was less than 10 and $20 \%$, respectively, in the 21-h mixture applications. Mixtures of fludioxonil and TBZ were highly effective when fruit were inoculated with the sensitive isolate, and efficacy was slightly improved compared with using fludioxonil alone after inoculation of fruit with the resistant isolate. Although TBZ was not evaluated as a singlefungicide treatment, fludioxonil was most likely the critical component in the fludioxonil-TBZ mixture in the decay control studies using the resistant isolate of the pathogen. Mixtures of imazalil with pyrimethanil were the most effective combination treatment using either isolate of $P$. digitatum in the inoculations (Fig. 1C and D). Still, because the efficacy of imazalil was reduced in inoculations with the resis-

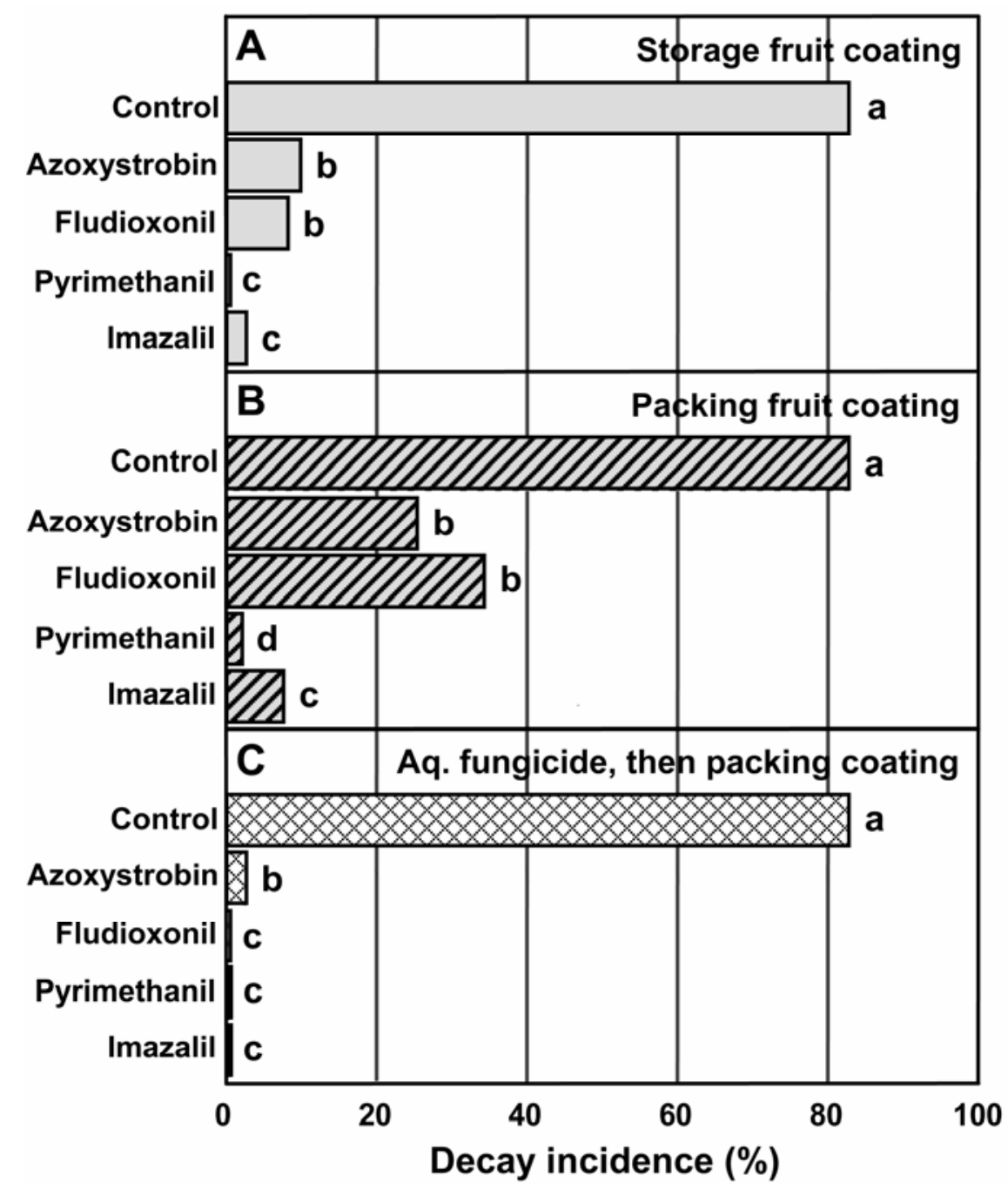

Fig. 4. Effect of postharvest fruit coatings on the efficacy of fungicides $(1,200 \mathrm{mg} /$ liter for azoxystrobin and fludioxonil, 1,000 mg/liter for imazalil and pyrimethanil) in managing green mold of lemon fruit in laboratory studies. Fruit were wound-inoculated with conidia of Penicillium digitatum $\left(20 \mu \mathrm{l}\right.$ of $10^{6}$ conidia/ml) of an imazalil/thiabendazole-sensitive isolate and treated after 13 to $15 \mathrm{~h}$ using fungicide solutions prepared in: $\mathbf{A}$, a diluted storage fruit coating; $\mathbf{B}$, a packing fruit coating; or $\mathbf{C}$, water with applications followed by packing fruit coating treatments. The incidence of fruit decay was evaluated after 6 to 7 days of incubation at $20^{\circ} \mathrm{C}$. Means followed by the same letter are not significantly different according to a general linear model analysis and LSD mean separation test $(P<0.05)$. tant isolate (ca. 30\% decay incidence in the $21-\mathrm{h}$ treatments as compared to $0 \%$ in inoculations with the sensitive isolate), pyrimethanil was the important component in the mixture.

These experiments identified critical application timings for each of the fungicides and mixtures in controlling decay caused by $P$. digitatum sensitive or resistant to the two older fungicides. Mixtures were highly effective, and their use generally is an important anti-resistance strategy. They should not be used, however, if resistance is already present against one of the mixture components (34). This is because with the reduced efficacy of TBZ and imazalil in the control of resistant pathogen populations, surviving resistant individuals will be under high selection pressure for any one of the new fungicides in these combination treatments. Thus, ideally, mixtures should be designed based on the sensitivity of the pathogen populations that are present in a specific environment.

Oranges, grapefruit, and mandarins are generally marketed soon after harvest and are treated only once with fungicides. Lemons, however, are often stored for several months before marketing, and thus, they are treated with postharvest fungicides before storage and before leaving the packinghouse. Fungicide applications are usually done in a fruit coating to prevent moisture loss (i.e., use of storage fruit coating) or to improve fruit appearance for marketing (i.e., use of packing fruit coating). Therefore, the efficacy of treatments for decay control in our study was compared using different fungicide preparations and use strategies. In the laboratory studies, single-fungicide treatments were evaluated for control of decay caused by the imazalil/TBZ-sensitive isolate to determine any interaction with the fruit coating. Mixture treatments were evaluated for control of decay caused by the resistant isolate because resistant isolates commonly occur in packinghouses. Efficacy was significantly lower when fungicides were mixed into the packing fruit coating because, apparently, the active ingredients are not soluble in this nonaqueous, shellacbased fruit coating. In contrast, all singlefungicide and mixture treatments consistently resulted in the lowest incidence of green mold decay when applied as aqueous solutions that were followed by the packing fruit coating. In this application strategy for single fungicides, fludioxonil, pyrimethanil, and imazalil with $\leq 1 \%$ decay incidence were somewhat more effective than azoxystrobin with $6 \%$ decay incidence (Fig. 4C). Of the combination treatments, the azoxystrobin-fludioxonil mixture was equally effective as the imazalilpyrimethanil mixture, and the incidence of green mold was $\leq 3.5 \%$ (Fig. 5C). Smoot and Melvin (32) evaluated the effect of the following three application regimes using benomyl on oranges: in storage fruit coat- 
ing (i.e., water wax), in packing fruit coating (i.e., solvent wax), and aqueous applications before fruit coating treatments. Although effective control was obtained by all three methods, applications in storage fruit coating and aqueous applications before fruit coating treatments were more efficacious than benomyl in packing fruit coating. In other studies, aqueous treatments with pyrimethanil (29) or heated aqueous treatments with imazalil (30) were also more effective than applications in fruit coating. In our study, similar results were obtained using the new fungicides, as well as imazalil and TBZ. Fungicide preparations in storage fruit coating had an intermediate efficacy between preparations in packing fruit coating and aqueous treatments that were followed by packing fruit coating.

Because fungicide mixtures are critical in resistance management, they were further evaluated in an experimental packingline study where aqueous in-line fungicide drenches were followed by a treatment with storage or packing fruit coating. These two-step applications were all very effective in reducing decay caused by the resistant isolate of $P$. digitatum. In contrast to the laboratory studies where fungicides were mixed directly with the storage fruit coating, there were no significant differences in efficacy between both application strategies in the experimental packingline study. Thus, these studies that identified incompatibilities of fungicides with fruit coatings indicate that for maximum decay control, fungicides should be applied in a two-step procedure before storage or before marketing using the respective fruit coating.

The enormous reproductive capacity of $P$. digitatum combined with the layout of most citrus packinghouses, which allows a continuous flow of airborne conidia from decayed fruit throughout the entire operation, as well as the almost year-round processing of fruit in California citrus packinghouses, provide a high potential for infection of healthy fruit in the packinghouse facility at several points during washing, storing, and packing $(4,15,24)$. Therefore, another important aspect of decay management in citrus fruit is to prevent sporulation of $P$. digitatum on the fruit surface and, subsequently, to reduce soiling and contamination of the adjacent fruit during shipment and marketing. In our evaluations of the anti-sporulation activity of the fungicides, fruit were inoculated at the center using a syringe. This was done to ensure a high decay incidence of all treated fruit. This way, the degree of sporulation on the fruit surface could be evaluated on most of the inoculated fruit, in contrast to when fruit were inoculated into small wounds in the rind and decay development was inhibited by the treatments.

Among the three new fungicides evaluated as aqueous treatments, azoxystrobin provided the best anti-sporulation activity.

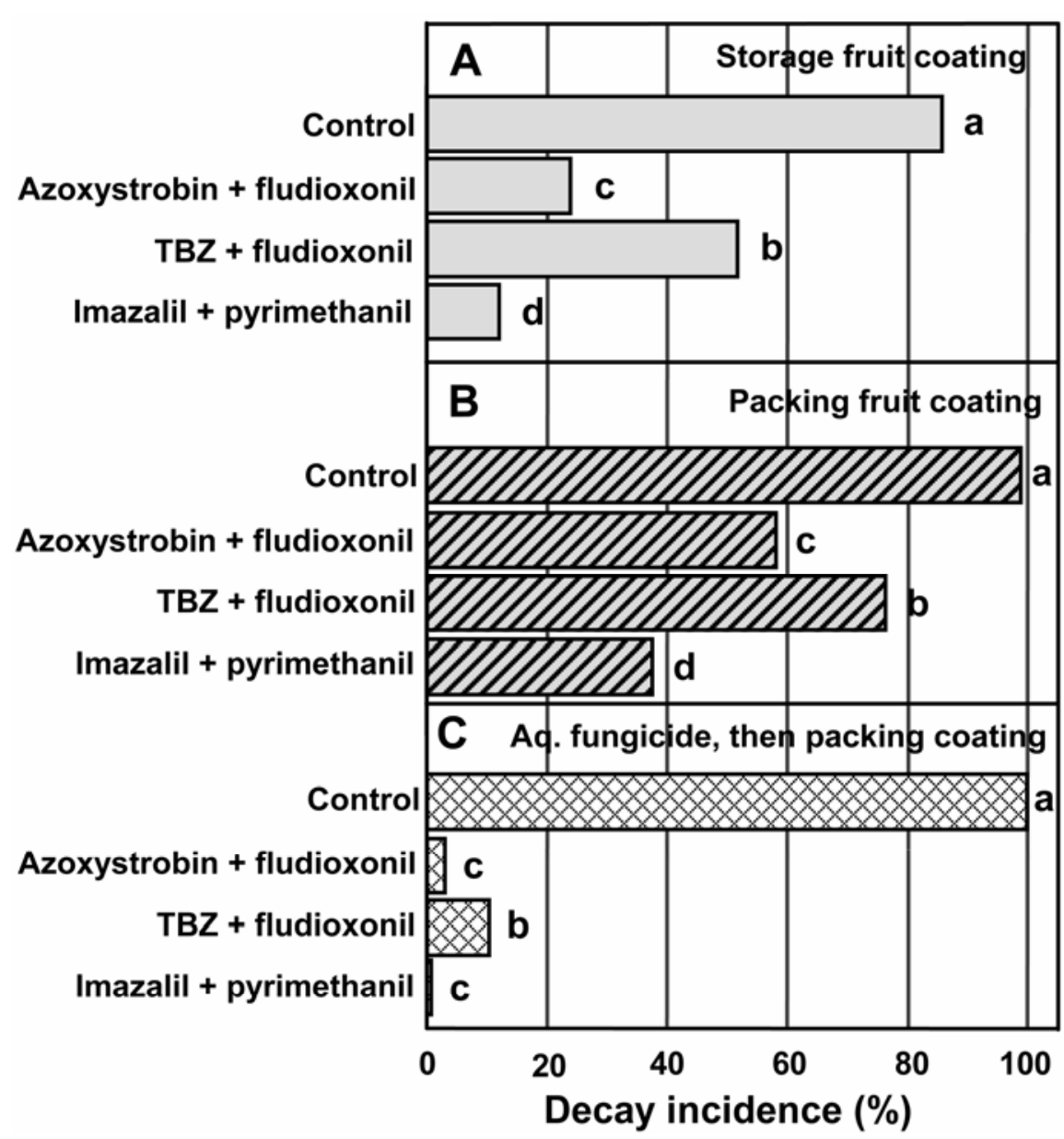

Fig. 5. Effect of postharvest fruit coatings on the efficacy of selected fungicide mixtures $(500 \mathrm{mg} / \mathrm{liter}$ for each fungicide) in managing green mold of lemon fruit in laboratory studies. Fruit were woundinoculated with conidia of Penicillium digitatum $\left(20 \mu \mathrm{l}\right.$ of $10^{6}$ conidia/ml) of an imazalil/thiabendazole-resistant isolate and treated after 13 to $15 \mathrm{~h}$ using fungicide solutions prepared in: A, a diluted storage fruit coating; $\mathbf{B}$, a packing fruit coating; or $\mathbf{C}$, water with applications followed by packing fruit coating treatments. The incidence of fruit decay was evaluated after 6 to 7 days of incubation at $20^{\circ} \mathrm{C}$. Means followed by the same letter are not significantly different according to a general linear model analysis and LSD mean separation test $(P<0.05)$.

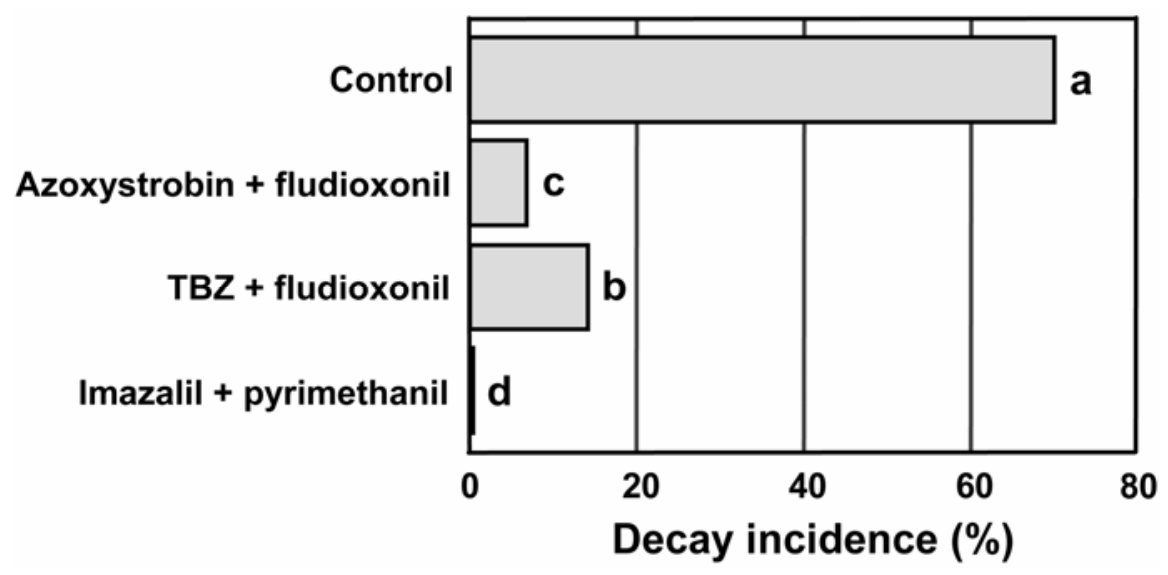

Fig. 6. Effect of postharvest fruit coatings on the efficacy of selected fungicide mixtures $(500$ $\mathrm{mg} / \mathrm{liter}$ for each fungicide) in managing green mold of lemon fruit in experimental packingline studies. Fruit were wound-inoculated with conidia of Penicillium digitatum $\left(20 \mu \mathrm{l}\right.$ of $10^{6}$ conidia/ml) of an imazalil/thiabendazole-resistant isolate and treated after 13 to $14 \mathrm{~h}$ using aqueous in-line fungicide drenches that were followed by a fruit coating. The incidence of fruit decay was evaluated after 6 to 7 days of incubation at $20^{\circ} \mathrm{C}$. Means followed by the same letter are not significantly different according to a general linear model analysis and LSD mean separation test $(P<0.05)$. 
Average sporulation for the sensitive $P$. digitatum isolate was rated as 1.74 on a 0 to 4 scale, while for the resistant isolate it was 1.0. An index of about 1.0 is an acceptable level of sporulation control for a citrus postharvest fungicide (J. E. Adaskaveg, unpublished). Storage fruit coating applications improved the anti-sporulation activity of azoxystrobin. Fludioxonil had a moderate anti-sporulation activity when applied in water-based treatments, but its activity was improved when applied in storage fruit coating-based treatments. Pyrimethanil, whether applied in an aqueous or a storage fruit coating suspension, had the lowest anti-sporulation activity of the compounds evaluated (although it was used at a slightly lower rate than azoxystrobin or fludioxonil), and its activity was reduced with the use of a fruit coating as compared to aqueous applications. Others have previously reported inadequate anti-sporulation activity of pyrimethanil (29), and this characteristic should limit this fungicide's use under practical conditions when sporulation control is critical, such as for storage treatments of lemon fruit. Sporulation was more effectively controlled by TBZ in a fruit coating formulation than in an aqueous suspension of the same concentration, apparently because the former resulted in larger deposits of thiabendazole on the surface of the treated fruit $(13,21)$. Thus, as in our studies, the performance of fungicides in inhibiting sporulation was dependent on the properties of the individual fungicides.

Similar to single-fungicide applications, the anti-sporulation activity of mixtures was dependent on the particular fungicide mixture and the use of a fruit coating. Mixtures of azoxystrobin with fludioxonil overall had the highest anti-sporulation activity in aqueous and storage fruit coating applications when either isolate of $P$. digitatum was used for inoculation. The TBZ-fludioxonil mixture applied in the storage fruit coating also provided very good sporulation control using both isolates of $P$. digitatum in inoculations. In contrast, the mixture of imazalil with pyrimethanil exhibited a reduced antisporulation activity when prepared in diluted storage fruit coating. This confirms earlier reports that the effectiveness of imazalil is slightly reduced in storage or packing fruit coating formulations, and this apparently is related to the reduced movement of the fungicide in the fruit coating and the limited penetration into the fruit peel (6). Furthermore, pyrimethanil in the imazalilpyrimethanil mixture provided little sporulation activity against the resistant isolate whether in an aqueous or storage fruit coating application. Therefore, the use of pyrimethanil in mixtures with imazalil (i.e., the currently available premixture product Philabuster) for anti-sporulation activity will be dependent on the strains of $P$. digitatum present in the packinghouse.
In this study, we characterized the decay control and anti-sporulation properties, as well as the compatibility of azoxystrobin, fludioxonil, and pyrimethanil with postharvest fruit coatings that will determine their most efficient usage patterns. Thus, as a storage treatment, where decay as well as sporulation on any decaying fruit should be minimized, azoxystrobin and fludioxonil would be preferable. Because pyrimethanil had poor anti-sporulation activity, this fungicide would be best used in treatments of fruit before marketing. The use of imazalil and TBZ will depend on the occurrence of resistance in a specific environment. The use of fungicide mixtures (active ingredients with different modes of action) that are rotated between storage and packing applications will be the ultimate strategy in resistance management. Because the different fungicides are owned by different registrants, and because of the costs of the individual fungicides, however, limitations will occur in the design and use of tank mixtures.

The simultaneous introduction of three new fungicides for postharvest green mold control of citrus fruit provides a unique opportunity for effective, long-term decay management. Historically, fungicides for citrus decay control were introduced individually over many years, SOPP in the 1930s, TBZ in the early 1970s, and imazalil in the early 1980s. This occurred after resistance to the previously registered material had already developed. In this case, resistance for the newly introduced fungicide could readily be selected for, because selection was targeted against another single-site mode of action material. With the introduction of three new fungicides, effective mixture and rotation programs can be designed that could delay the onset of resistance development against these new compounds $(10,34)$. In addition, the seasonal increase in the incidence of resistance against the older materials (J. E. Adaskaveg, unpublished) might be delayed. Thus, imazalil and TBZ will remain important management tools and can be incorporated into management programs. Because pathogen populations are periodically being monitored for their resistance in many packinghouses, imazalil and TBZ can still be effectively used if resistance levels against these fungicides are low, as it commonly occurs early in the packing season (i.e., September to December under California conditions). Ideally, integrated management programs using all five fungicides should be developed for each packinghouse based on monitoring of fungicide sensitivity in $P$. digitatum populations and rotations of mixtures of products with different modes of action.

\section{ACKNOWLEDGMENTS}

This research was financially supported by the California Citrus Research Board. We also thank Bayer CropScience, Decco-Cerexagri Inc., Janssen Pharmaceutica, and Syngenta Crop Protection for supplying fungicides, financial support, and technical information. The assistance of Alejandra SotoEstrada, Monica Dirac, and Edgar E. Romo in the laboratory studies and of George Driever in the experimental packingline studies is gratefully acknowledged. This research is part of a Ph.D. dissertation undertaken by Loukas Kanetis

\section{LITERATURE CITED}

1. Adaskaveg, J. E., and Förster, H. 2004. New reduced-risk postharvest fungicides for management of gray and blue molds of pears and their use in fungicide resistance management. (Abstr.) Phytopathology 94:S149.

2. Adaskaveg, J. E., Förster, H., and Sommer, N. F. 2002. Principles of postharvest pathology and management of decays of edible horticultural crops. Pages 163-195 in: Postharvest Technology of Horticultural Crops. A. A. Kader, tech. ed. University of California, Agriculture and Natural Resources, Oakland, CA Publ. no. 3311.

3. Adaskaveg, J. E., Kanetis, L., Soto-Estrada, A., and Förster, H. 2004. A new era of postharvest decay control in citrus with the simultaneous introduction of three new "reduced-risk" fungicides. Pages 999-1004 in: Proc. Int. Soc. Citric.

4. Bancroft, M. N., Gardner, P. D., Eckert, J. W. and Baritelle, J. L. 1984. Comparison of decay control strategies in California lemon packinghouses. Plant Dis. 68:24-28.

5. Bartlett, D. W., Clough, J. M., Godwin, J. R. Hall, A. A., Hamer, M., and Parr-Dobrzanski, B. 2002. Review: The strobilurin fungicides. Pest Manag. Sci. 58:649-662.

6. Brown, G. E., Nagy, S., and Maraulja, M 1983. Residues from postharvest nonrecovery spray applications of imazalil to oranges and effect on green mold caused by Penicillium digitatum. Plant Dis. 67:954-957.

7. Bus, V. G., Bongers, A. J., and Risse, L. A 1991. Occurrence of Penicillium digitatum and $P$. italicum resistant to benomyl, thiabendazole, and imazalil on citrus from different geographic origins. Plant Dis. 75:1098-1100.

8. Bushong, P. M., and Timmer, L. W. 2000. Evaluation of postinfection control of citrus scab and melanose with benomyl, fenbuconazole, and azoxystrobin. Plant Dis. 84:1246-1249.

9. Cochran, A., Tally, A., Tedford, E., and Adaskaveg, J. E. 2006. Azoxystrobin: A new postharvest decay control tool for citrus. (Abstr.) Phytopathology 96:S167.

10. Dekker, J. 1986. Preventing and managing fungicide resistance. Pages 347-354 in: Pesticide Resistance: Strategies and Tactics for Management. Committee on Strategies for the Management of Pesticide Resistant Pest Populations, Board of Agriculture, National Research Council, ed. National Academy Press, Washington, DC

11. Eckert, J. W. 1982. Case study 5: Penicillium decay of citrus fruit. Pages 231-250 in: Fungicide Resistance in Crop Protection. J. Dekker and S. G. Georgopoulos, eds. Centre for Agricultural Publishing and Documentation, Wageningen, The Netherlands.

12. Eckert, J. W., and Eaks, I. L. 1989. Postharvest disorders and diseases of citrus fruit. Pages 179-260 in: The Citrus Industry, Vol. V - Crop Protection, Postharvest Technology, and Early History of Citrus Research in California. W. Reuther, E. C. Calavan, and G. E. Carman, eds. University of California, Division of Agricultural and Natural Resources, Oakland, CA. Publ. no. 3326.

13. Eckert, J. W., and Kolbezen, M. J. 1977. Influence of formulation and application method on the effectiveness of benzimidazole fungicides for controlling postharvest diseases of citrus fruit. Neth. J. Plant Pathol. 83 (Suppl. 1):343-352.

14. Eckert, J. W., and Sommer, N. F. 1967. Control of diseases of fruit and vegetables by posthar- 
vest treatment. Annu. Rev. Phytopathol. 5:391432.

15. Eckert, J. W., and Wild, B. L. 1983. Problems of fungicide resistance in Penicillium rot of citrus fruit. Pages 525-556 in: Pest Resistance to Pesticides. G. P. Georghiou and T. Saito, eds. Plenum Publishing Corp., New York.

16. Environmental Protection Agency (EPA) 1998. General overview: Reduced risk pesticide program. Environ. Prot. Agency Off. Pestic. Programs, Staff Background, Pages 2-4.

17. Errampalli, D. 2004. Effect of fludioxonil on germination and growth of Penicillium expansum and decay in apple cvs. Empire and Gala. Crop Prot. 23:811-817.

18. Errampalli, D., and Crnko, N. 2004. Control of blue mold caused by Penicillium expansum on apples 'Empire' with fludioxonil and cyprodinil. Can. J. Plant Pathol. 26:70-75.

19. Förster, H., Driever, G. F., Thompson, D. C., and Adaskaveg, J. E. 2007. Postharvest decay management for stone fruit crops in California using the 'reduced-risk' fungicides fludioxonil and fenhexamid. Plant Dis. 91:209-215.

20. Gullino, M. L., Leroux, P., and Smith, C. M. 2000. Review: Uses and challenges of novel compounds for plant disease control. Crop Prot. 19:1-11.

21. Gutter, Y., Yanko, U., Davidson, M., and Rahat, M. 1974. Relationship between mode of application of thiabendazole and its effectiveness for control of green mold and inhibiting fungus sporulation on oranges. Phytopathology 64:1477-1478

22. Harding, P. R., Jr. 1962. Differential sensitivity to sodium orthophenylphanate by biphenylsensitive and biphenyl-resistant strains of Penicillium digitatum. Plant Dis. Rep. 46:100104.

23. Harding, P. R., Jr. 1972. Differential sensitivity to thiabendazole by strains of Penicillium digitatum. Plant Dis. Rep. 56:256-260.

24. Holmes, G. J., and Eckert, J. W. 1999. Sensitivity of Penicillium digitatum and P. italicum to postharvest citrus fungicides in California. Phytopathology 89:716-721.

25. Ma, Z. H., Felts, D., and Michailides, T. J. 2003. Resistance to azoxystrobin in Alternaria isolates from pistachio in California. Pestic. Biochem. Physiol. 77:66-74.

26. Rosslenbroich, H. J., and Stuebler, D. 2000. Botrytis cinerea - history of chemical control and novel fungicides for its management. Crop Prot. 19:557-561.

27. Sholberg, P. L., Bedford, K. E., and Stokes, S. 2003. Effect of preharvest application of cyprodinil on postharvest decay of apples caused by Botrytis cinerea. Plant Dis. 87:10671071.

28. Sholberg, P. L., Bedford, K., and Stokes, S. 2005. Sensitivity of Penicillium spp. and $\mathrm{Bo}$ trytis cinerea to pyrimethanil and its control of blue and gray mold of stored apples. Crop Prot. 24:127-134
29. Smilanick, J. L., Mansour, M. F., Mlikota Gabler, F., and Goodwine, W. R. 2006. The ef fectiveness of pyrimethanil to inhibit germination of Penicillium digitatum and to control citrus green mold after harvest. Posth. Biol. Technol. 42:75-85.

30. Smilanick, J. L., Michael, L. F., Mansour, M. F., Mackey, B. E., Margosan, D. A., Flores, D. and Weist, C. F. 1997. Improved control of green mold of citrus with imazalil in warm water compared with its use in wax. Plant Dis. 81:1299-1304.

31. Smoot, J. J., Houck, L. G., and Johnson, H. B. 1971. Market Diseases of Citrus and Other Subtropical Fruits. U.S. Dep. Agric. Agric. Handb. No. 398

32. Smoot, J. J., and Melvin, C. F. 1974. Decay control of oranges with benomyl by three methods of postharvest application. Fla. State Hortic. Soc. 88:234-236.

33. Uesugi, Y. 1998. Fungicide classes: Chemistry, uses and mode of action. Pages 23-56 in: Fungicidal Activity - Chemical and Biological Approaches to Plant Protection, D. Hutson and J. Miyamoto, eds. John Wiley \& Sons, New York.

34. Wade, M. 1988. Strategies for preventing or delaying the onset of resistance to fungicides and for managing resistance occurrences. Pages 14-15 in: Fungicide Resistance in North America. C. J. Delp, ed. American Phytopathological Society, St. Paul, MN 